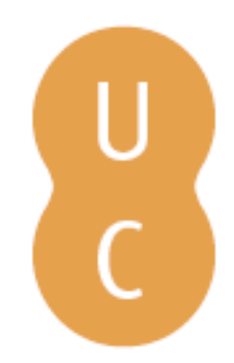

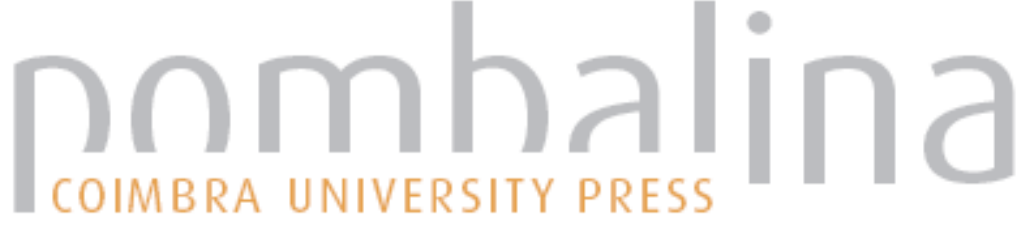

\section{A especificidade do educativo: seu potencial teórico e prático}

Autor(es): $\quad$ Boavida, João; Amado, João

Publicado por: Imprensa da Universidade de Coimbra

URL

persistente: URI:http://hdl.handle.net/10316.2/38379

DOI: $\quad$ DOI:http://dx.doi.org/10.14195/978-989-26-0486-2_1

Accessed : $\quad$ 26-Apr-2023 13:40:23

A navegação consulta e descarregamento dos títulos inseridos nas Bibliotecas Digitais UC Digitalis, UC Pombalina e UC Impactum, pressupõem a aceitação plena e sem reservas dos Termos e Condições de Uso destas Bibliotecas Digitais, disponíveis em https://digitalis.uc.pt/pt-pt/termos.

Conforme exposto nos referidos Termos e Condições de Uso, o descarregamento de títulos de acesso restrito requer uma licença válida de autorização devendo o utilizador aceder ao(s) documento(s) a partir de um endereço de IP da instituição detentora da supramencionada licença.

Ao utilizador é apenas permitido o descarregamento para uso pessoal, pelo que o emprego do(s) título(s) descarregado(s) para outro fim, designadamente comercial, carece de autorização do respetivo autor ou editor da obra.

Na medida em que todas as obras da UC Digitalis se encontram protegidas pelo Código do Direito de Autor e Direitos Conexos e demais legislação aplicável, toda a cópia, parcial ou total, deste documento, nos casos em que é legalmente admitida, deverá conter ou fazer-se acompanhar por este aviso.

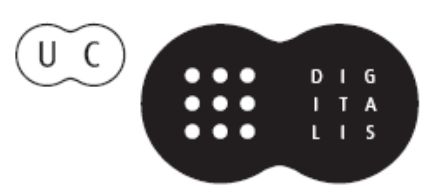


João Boavida

Ángel García del Dujo

Coordenação

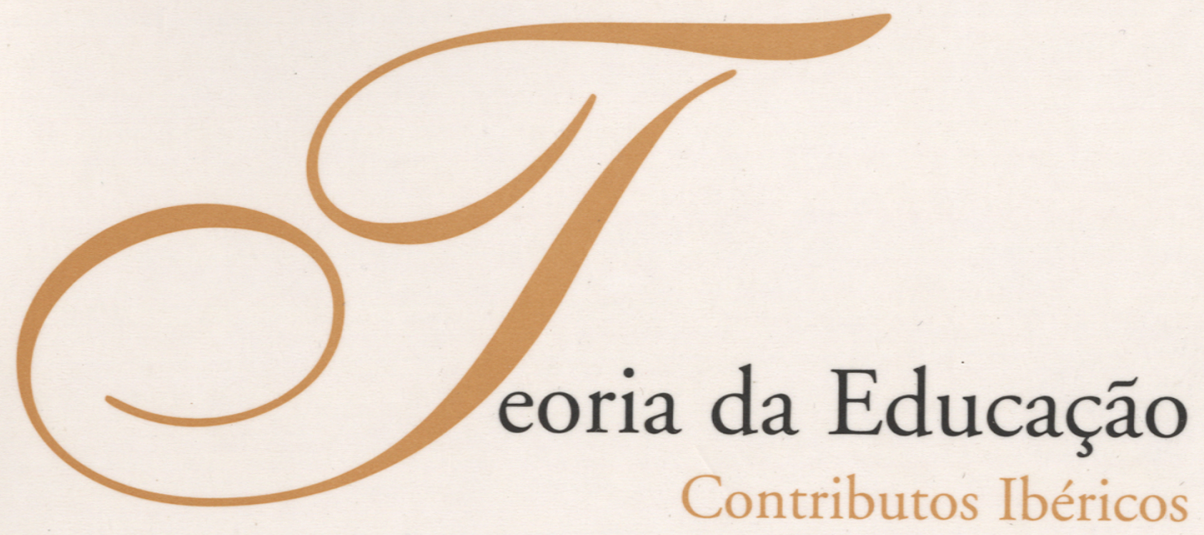


João Boavida

João A mado

Universidade de Coimbra

A Especificidade do Educativo

Seu Potencial Teórico e Prático

Dada a importância e a centralidade do fenómeno educativo nos nossos dias é inevitável teorizar sobre ele. A questão da necessidade da teoria, ou da sua importância relativamente a uma prática, tem tendência a ser desvalorizada pelo pensamento corrente devido à excessiva valorização que se faz desta última. De facto, não podemos deixar de teorizar sobre uma fenómeno com tais implicações individuais, sociais, culturais e económicas. Pensar sobre a educação (o que ela é, a sua natureza específica, como deve ser conduzida, etc.) acaba por ser a atitude inevitável sempre que surjam problemas neste campo, ou sempre que tenhamos consciência deles. No limite haverá tantas teorias sobre a educação quantos os problemas que ela possa levantar nos múltiplos domínios em que se manifesta; sem deixar de haver necessariamente muitas linhas de convergência e múltiplos planos sobrepostos, até pelos contextos culturais em que todas necessariamente se integram. Facto que produz, em cada época, concepções predominantes e cosmovisões mais ou menos generalizadas, e cuja análise implica, obviamente, mais teorização. A qual nunca deixa de ser feita, embora 0 possa ser de muitos modos e em muitos níveis (Wilson, 2003). Ora, quer numa perspectiva de análise das práticas correntes, quer numa teoria do que a educação deva ser, e das práticas daí resultantes, a actividade de teorização é inerente tanto aos actos de educar e de ser educado, como ao acto único 
de educar e de ser educado, sem esquecer, obviamente, a Educação em si mesma com toda a sua complexidade. Esta situação exige, porém, um outro nível de análise. De facto, há em todas as inúmeras situações educativas em que a prática se concretiza, e em todas as abordagens que pressupõem a teoria, um residual comum a todas as situações educativas susceptível de ser teorizado, que diz respeito à natureza do educativo em si mesmo, e que ainda não vimos conceptualizado. É este elemento radical que vai ser 0 objecto desta nossa reflexão.

\section{Do especificamente educativo e suas características}

\subsection{Do conceito em geral}

Entendemos por especificamente educativo o educativo em si mesmo, tudo aquilo que não é susceptível de catalogação de outra maneira ou de integração noutra área que não a educativa, sendo, em todas as situações aparentadas ou próximas das situações educativas, aquilo que nelas, apesar de toda a sua diversidade, é comum. Em suma, entendemos por especificamente educativo o denominador comum de natureza educativa que, enquanto tal, se mantém constante em todas as situações e se manifesta por um conjunto de características comuns em todas as abordagens.

Sendo assim, numa prévia tentativa de conceptualização e num registo já um pouco diferente, podemos pensar no especificamente educativo como aquilo que não se esgota em nenhuma situação educativa em concreto mas está presente em todas elas. Transcende 0 circunstancial de cada uma e permanece em todas como um núcleo e um potencial específico; permitindo, por um lado, identificar e classificar todas as situações como educativas ou não, por muito variadas que sejam, e, por outro, conceber 0 educativo com uma entidade própria que ultrapassa as situações e relações em que se manifesta. 
Perspectivando a questão por outro lado: nenhuma situação esgota 0 educativo que tem em si, porque este não se identifica completamente com 0 carácter concreto e único de cada situação educativa, embora se reconheçam estas situações por algo que está em todas mas transcende cada uma delas na sua situação particular. Com efeito, dado o carácter concreto e individual de todas as situações, o educativo aparece sempre contextualizado e inserido em situações determinadas; embora todos facilmente possamos reconhecer a natureza, educativa ou não, de uma situação ou atitude, separando o concreto de uma situação, da ideia que nos permite identificá-la como educativa. Ao separar 0 concreto de uma situação das características educativas que nela podemos descobrir, estamos a identificar 0 especificamente educativo e a conceder-lhe um estatuto teoricamente autónomo. Do que estamos à procura é de compreender em que consiste tornar-se e desenvolver-se alguém como pessoa tendo em conta 0 esforço educacional (Uljens, 2002), pondo entre parêntesis os contextos e as situações em que isso sempre se verifica. Esta simples constatação corrente parece-nos guardar uma dimensão ontológica da teoria da educação, e que se manifesta no acto educativo, para além de ser uma dimensão epistemológica e com importantes consequências para a identidade das ciências que sobre 0 acto educativo se ocupam.

Uma primeira abordagem do conceito na tentativa de 0 compreender obriga-nos a formular de imediato três perguntas:

1. a: onde será visível o especificamente educativo?

2. a: em que consistirá?

3. a: como se manifestará ele?

Quanto à l.a pergunta, poderemos dizer que ele é visível ou detectável em todas as situações educativas, e que é justamente 0 educativo dessas situações que, possibilitando-nos a sua identificação, torna visível aquela qualificação. Ou seja, embora nem sempre 0 vejamos, ele é detectável a posteriori pela análise de qualquer situação quando nela 0 educativo 
se reconhece e sempre que nela se reconheça. Uma qualquer situação ou relação, mesmo não intencionalmente educativa, mas em que se reconheçam,

ou se venham a reconhecer essas componentes e efeitos, manifesta 0 específicamente educativo que nela existe, apesar de a situação não ter intenções educativas à partida, ou de não apresentar essas características para muita gente, mas tê-las para quem proceda a uma análise mais detalhada ou de maior sensibilidade às questões educativas e suas características. 0 educativo de uma dada situação pode, pois, não existir para uns e existir para outros, o que significa que há ali uma dimensão que se pode reconhecer por algumas características particulares.

De outro modo. Se uma dada situação, relação ou atitude é educativa para certas pessoas e não é para outras, ou é educativa em certas condições e já não é noutras, ou começou por ser educativa e deixou de ser; ou, inversamente, começou por não ser educativa mas depois revelou-se como tal, há, em todos estes casos, uma dimensão específica que nos permite fazer estas análises e conseguir estas identificações, apesar da oscilação constante de fronteiras entre 0 educativo e 0 que não é educativo; há como que um eixo comum em volta do qual todas estas situações se desenvolvem ou ao qual se referem. A sua natureza está dependente de factores, objectivos e subjectivos, que umas vezes estão presentes e outras não, mas que, desde que funcionando dentro de certas condições, e com uma conotação mínima, permitem compreender o estatuto do educativo, incerto, difícil de definir, mas indispensável para que a uma qualquer situação seja atribuível essa função e, portanto, essa qualidade.

Tornando-se 0 educativo visível pelo reconhecimento de certas características, estamos em condições, pelo menos em parte, de responder à segunda pergunta: em que consistirá ele? E só em parte, porque reconhecer que uma situação é educativa, ou que 0 pode ser, embora nos dê condições para tentar saber em que consistirá isso, não nos permite uma definição rigorosa porque, como já vimos, o educativo manifesta-se por um residual que está para lá de qualquer situação, pois não se identifica por completo, 
nem pode identificar, com nenhuma em particular. Ora, se 0 especificamente educativo consiste naquilo que de educativo há em todas as situações que de educativo tenham qualquer coisa, mas que não se confunde nem identifica com 0 concreto de nenhuma delas, se é 0 residual de todas as situações educacionais, por muito diversas que sejam, aquilo que 0 identifica em cada situação não é aquilo que em cada situação é único, mas 0 que em cada situação, sendo especificamente educacional, não pode ser integrável noutra categoria, e mesmo que só ali e naquelas condições particulares aconteça e se manifeste.

Isto é, ao compreender 0 educativo de uma dada situação fazemo-lo emergir já com um estatuto diferente do que detém naquela situação concreta, o que revela uma entidade essencialmente possível, facto que torna impossível uma definição, embora não impossibilite 0 conceito. Ou seja, 0 que caracteriza 0 educativo é 0 que nos permite detectá-lo para lá e independentemente de todos os elementos concretos e de todas as situações; sendo certo que, todavia, são estes elementos que possibilitam a identificação do educativo de uma dada situação. Sendo assim, podemos dizer que 0 educativo é 0 que está em todas as situações educativas, mas não está, em si mesmo, em nenhuma dessas situações. Está em todas, porque nenhuma 0 poderá ser sem possuir uma qualquer especificidade que permita identificá-la como tal; e não está em nenhuma pela razão de que nenhuma situação contém, à partida, 0 especificamente educativo. De facto, nem todas as situações dadas à partida como educativas, ou pensadas e previstas como tal, 0 vêm a ser efectivamente, enquanto outras, que não eram para 0 ser, se transformaram nisso, ou ainda, só foram educativas para certas pessoas e em certos momentos, como já referimos. 0 que permite dizer, no que diz respeito à terceira pergunta, que 0 educativo se manifesta de tantas maneiras quantas formos capazes de reconhecer, na sua «educatividade», e sempre que isso acontecer. Em suma, o estatuto ontológico do especificamente educativo transcendente necessariamente as situações particulares sem nunca viver fora delas. 


\subsection{As constantes do processo educativo}

Considerando que não há educação sem um conjunto de condições, por poucas que sejam, e que sempre as actividades educativas manifestarão um mínimo de características constantes, aquelas que são indispensáveis para que uma qualquer situação seja educativa, poderemos perguntar: 0 que será o mínimo comum indispensável a qualquer situação desta natureza?

Será aquilo que resulta de um conjunto de pressupostos, de um certo número de condições e de intenções, que não são visíveis mas existem, e sem os quais não haveria educação; aquilo que efectivamente se faz, ou alguém faz, quando educa e sempre que educa; e as consequências que alguém é capaz de tirar, ao nível e com a profundidade de que for capaz.

Parece, pois, que haverá um antes —os pressupostos, as condições e as intenções; um durante, 0 acto ou situação educativa constituída por modos e métodos educativos; e um depois, que é a possibilidade de avaliação ou de comparação com um estádio anterior. 0 específicamente educativo de que andamos à procura resultará assim da combinação destes elementos.

\subsubsection{Os pressupostos e as condições}

0 que são, como se distinguem, e como se relacionam os pressupostos e as condições do acto educativo?

Conceitos como acção, sentido, finalidade, consciência, opção, liberdade, responsabilidade, exigência, hierarquia, valor, etc., são conceitos que não se podem identificar com a situação educativa, porque noutras situações podem também aparecer, mas que pressupomos sempre que pensamos em educação ou actuamos educativamente, e que sofremos quando somos sujeitos a qualquer acção educativa.

Não quer dizer que todos estejam sempre presentes em qualquer acção educativa, mas sim que pressupomos sempre um número mínimo necessário para que uma dada situação seja educativa, e se possa reconhecer como tal. 
E pressupomos quais? E porquê esses e não outros? A decisão não é arbitrária. Pressupomos justamente aqueles que, determinando e configurando aquela situação ou acção, a tornam educativa e a revelam como tal.

0 pressuposto educativo é assim uma componente do especificamente educativo, é aquilo que de algum modo o prepara na medida em que 0 condiciona, é a predisposição para a inserção no registo relacional da transformação de comportamentos que identificamos com educação. É aquilo em que implicitamente pensamos quando pensamos em educação, mesmo que nisso não pensemos de forma explícita; ou aquele mínimo em que não deixamos de pensar ou pressupor quando pensamos, sentimos ou actuamos educativamente. Ou inversamente, aquilo cuja aplicação ou desenvolvimento produz, ou tem possibilidades de produzir, uma situação educativa; e apresenta as características que lhe referimos, porque faz parte das situações educativas, pertence-lhes por natureza, sem de facto se identificar com nenhuma.

0 pressuposto é 0 que se entende implicitamente por educativo quando se fala de educação, o que subjaz ao pensamento, ao acto e à razão de ser de ambos. E mais, 0 pressuposto à relação educativa é 0 que se compreende de uma situação que se entende ser educativa pelas suas características e sem 0 qual não 0 seria. Sendo assim, 0 pressuposto não está tanto na relação educativa quanto em nós, (visto sermos nós que damos ou tiramos 0 educativo às situações) embora 0 reconheçamos sempre e 0 saibamos constitutivo de cada uma dessas relações, e, por isso, o pressuposto é anterior às situações; não, porém, em termos temporais mas intencionais.

Não devemos, por outro lado, confundir os pressupostos educativos com as condições educativas, embora estas acompanhem os pressupostos enquanto factores indispensáveis para que as possibilidades educacionais de uma certa situação se concretizem educativamente. Por condição entende-se todo e qualquer conjunto de circunstâncias que não só tornam educativamente possível uma situação, como levam a compreender que uma situação pode ser educativa, e de que modo e porquê poderá sê-lo. Assim, devemos 
considerar a condição como aquilo sem 0 qual a concretização educativa não é possível, podendo, talvez por isso, associar pressupostos e condições na ideia de intenção educacional, que, todavia, e como veremos a seguir, é diferente tanto dos pressupostos como das condições. Aquilo que torna possível qualquer acto educativo, ou que faz com que uma intenção se transforme em acto, também não é a educação propriamente dita, porque não é nenhum dos seus actos em concreto, mas não é possível educar ou pôr em prática qualquer acção educativa, ou obter resultados educativos de uma certa acção, sem as condições mínimas que a tornem possível. Sabemos, por outro lado, o quanto as condições educativas, favoráveis ou desfavoráveis, influenciam e condicionam 0 acto educativo e os seus efeitos, mas ninguém pode dizer rigorosamente até onde e de que modo isso acontece.

Os conceitos «pressuposto» educativo e «condição» educativa, que ressaltam de uma análise fenomenológica de qualquer situação educativa, embora diferentes, são vistos e sentidos como estando «antes» do acto educativo, como sendo prévios a toda a situação educativa, e, neste sentido, estão inerentes a um específico educativo e ajudam a defini-lo; fazem parte dele sem se identificarem de todo com ele. Por isso, dos pressupostos e das condições se pode dizer que fazem parte do acto educativo, visto nenhum acto educativo os poder dispensar. Mas além de não serem exclusivos do acto educativo, uma vez que não the pertencem especificamente e ambos são susceptíveis de ser ligados a situações não educativas, ninguém saberá calcular, em cada caso, o grau da sua influência, quando começam efectivamente a produzir educação, e quando terminam ou desaparecem, retirando a uma situação 0 educativo que ela continha.

0 especificamente educativo passa, sendo assim, por estas duas realidades que, em rigor, não lhe pertencem, mas que lhe são indispensáveis e que, nesta condição particular, 0 acompanham sempre. De facto, nem os pressupostos nem as condições têm realidade educativa fora destas situações; como é óbvio, o significado, nestas situações, é já outro. Ou seja, não é 0 educativo que necessariamente os define, mas este necessita deles para se definir. 
Não se identificam, portanto, com nenhuma situação educativa pois estão, de algum modo, sempre antes das situações, lógica e psicologicamente no caso dos pressupostos, e materialmente no caso das condições. A análise pode destacá-los dessas situações, e é isso que estamos a fazer, mas, enquanto tal, pressupostos e condições educativas só têm valor e significado educativo enquanto pertencem, e na medida em que pertencem, às situações e relações de natureza educativa.

\subsubsection{Da intenção como tensão}

Mas isto significa que a situação educativa é sempre mais que a mera realidade concreta que se pode observar e medir nela, e 0 que nela é mais significativo ou característico, para além dos pressupostos e das condições, é a intenção educacional, enquanto tensão dinâmica, enquanto energia.

Assim, poderemos considerar como educativa toda a situação em que se manifeste, ou que manifeste, uma intenção de aperfeiçoamento ou de qualificação, isto é, uma qualquer tensão capaz de dinamizar, num educando, um processo de aperfeiçoamento ou vontade de aprendizagem. Note-se que no caso da educação informal ou na educação espontânea não há, de facto, uma intenção explícita, mas não deixa de haver uma influência ou uma intenção implícita nos contextos culturais em que 0 indivíduo se insere e que, ao condicioná-lo nas atitudes (inibindo umas, reforçando outras), 0 orientam num certo sentido e nele promovem transformações comportamentais que a sociedade considera adequadas.

É esta intenção que faz educativos os pressupostos, e que congrega as condições necessárias para que 0 educativo 0 seja de facto, isto é, a situação educativa se concretize. Como diz Feldman, (2003) a intenção enquanto finalidade do acto educativo é «0 principal instrumento da actividade. É 0 que lhe dá, inicialmente, direcção e, constituindo parte instrumental dela, adequa-se e modifica-se no seu próprio desenrolar». Isto do lado do educador. Tal como, do lado do educando, é a avaliação dos actos e das situações, as consequências educativas que tira ou não das situações ou das acções, 
que as tornam ou não educativas. A intenção é a dinâmica que activa as enzimas que são os pressupostos e as condições; que, assim, poderão ser educativas se a intenção funcionar; e é a consequência que, pelo grau de valor que the damos e a capacidade de a assimilar, que irá transformar em educativa uma dada acção ou situação.

\subsubsection{Acto e relação educativa}

0 acto educativo nunca é abstracto, é sempre realizado por pessoas em determinados contextos e situações particulares, mas é indispensável ter como horizonte da nossa reflexão que, se é certo que nunca temos senão relações educativas concretas, o que aqui estamos a tentar é, mediante a análise, encontrar a relação educativa em si mesma e na forma mais depurada e simples da sua possibilidade. Por outro lado, também nunca é uma relação qualquer. Se da relação entre duas ou mais pessoas, ou entre situação e pessoa ou pessoas, resultar uma mudança comportamental que implique desenvolvimento e aperfeiçoamento, estamos face a uma relação educativa. Como a definiu Postic $(1984,12)$, «relação educativa é 0 conjunto das relações sociais que se estabelecem entre 0 educador e aqueles que educa para atingir objectivos educativos, numa dada estrutura institucional, relações essas que possuem características afectivas identificáveis, que têm um desenvolvimento e vivem uma história». Nesta definição não se esclarece quem está em jogo na relação educativa, quando, 0 quê e em que circunstâncias precisas ela tem lugar. Apenas se diz que há transmissão de saberes e normas de conduta que, supomos, servem para a sobrevivência e para a fruição. Relação educativa será assim o conjunto de interacções entre educador e educando, ou de influências de um sobre 0 outro, ou mútuas (influências dirigidas a uma finalidade construtiva), sejam quais forem as «naturezas» do educador e do educando, e por muito diversas que essas situações possam ser.

Os pressupostos, as condições, as intenções e as consequências não esgotam, porém, a situação educativa porque a situação, uma vez que é 
concreta, existe por si, sendo o educativo a componente que se lhe acrescenta ou se the retira, que reconhecemos nela, ou que nela não conseguimos descortinar. Não há acção educativa sem situação educativa concreta; não é, contudo, 0 concreto que dá a dimensão educativa, mas a dimensão abstracta (intenções, objectivos, sentimentos, emoções, significações, interpretações, repercussões...) que se lhe pode acrescentar; a qual nasce sempre, porém, da situação concreta. Assim, 0 antes e 0 depois de uma situação, embora condição indispensável para 0 seu carácter educativo, não são suficientes porque lhes falta 0 acto propriamente dito, a função educacional que se pode concretizar de muitas maneiras, e que já vimos só por si não ter condições para atribuir ou retirar a uma situação 0 educativo dela.

A acção educativa concreta faz parte do educativo, como é evidente, para muitos será até aqui que se concentra 0 efectivamente educativo, na medida em que é a acção que provoca os efeitos, pelo menos na aparência, mas não se esgota nisso, pela dimensão abstracta já referida. É neste momento que se coloca 0 problema do método pedagógico e da sua eficácia. Os métodos utilizados pelo educador são, como todos sabemos, da maior importância pela eficácia ou ineficácia que revelam e pelos efeitos positivos ou negativos que provocam, a tal ponto que a diferença entre uma boa e uma má educação, embora se possa chamar a ambas educação, pode chegar a ser oposta nos seus efeitos. Tanto no sentido de acabar por tirar todo 0 educativo a uma situação que foi pensada para educar e formar, como no sentido oposto de poder atribuir função educacional a atitudes, situações e relações que não tinham sido pensadas com essa intenção, 0 método educativo mostra não só a sua importância prática, mas até a capacidade de condicionar integralmente 0 estatuto educativo de uma situação ou relação. Como considera Pring $(2003,32)$ «existe uma estreita conexão entre 0 que se aprende e 0 processo pelo meio do qual se adquiriu essa aprendizagem». 0 mesmo autor considera ainda que a educação supõe um modo especificamente humano de aquisição de conhecimentos, crenças, atitudes e habilidades, o que quer dizer que não só a dimensão humana 
é indispensável para conferir significados educativos às situações, como a educação é também indispensável à própria condição humana.

No limite, poderemos dizer que os métodos, pelas potencialidades que têm e a amplitude de efeitos que podem provocar, (podendo ir da formação que ultrapassa 0 próprio mestre à negação de toda a educação e de toda a aprendizagem), guardam em si 0 estatuto educativo de uma situação. 0 método educativo mostra não só a sua importância prática, mas revela uma tal potencialidade teórica que acaba por condicionar integralmente 0 estatuto educativo de uma situação ou relação.

Também por este lado o específicamente educativo se revela volátil, podendo manifestar-se ou desaparecer conforme a acção dos agentes educativos em presença. A própria noção de agente educativo ganha assim um estatuto especial, porque não é educador quem quer ou assim se presume, nem sempre que 0 pretende, mas quem desempenha de facto, em qualquer situação, uma função de transformação para melhor, no educando, e também em si mesmo.

\subsubsection{As consequências da acção educativa}

0 processo educativo, na medida em que é um processo de aperfeiçoamento e de melhoria, pressupõe necessariamente a avaliação dos efeitos da acção, um cálculo explícito ou implícito dos resultados obtidos. Tenhamos ou não perfeita consciência disso, seremos levados a uma comparação entre 0 estádio anterior e 0 posterior, e isto de uma maneira contínua e simultânea ao próprio processo, fazendo parte dele. Mas como depende essencialmente do sujeito, da sua sensibilidade, capacidade interpretativa, em suma, da sua educação, 0 educativo está mais no grau, na perspectiva, na tonalidade e persistência dos efeitos (tudo isto bastante imprevisível) do que em resultados objectivos previamente determinados ou finalidades da acção; embora não deixe de ter também uma componente objectiva pela determinação social da educação, uma vez que avaliar as consequências requer critérios ou parâmetros. Porém, a graduação da dimensão social e a sua evolução, a sua variação em função 
de épocas e lugares, revela até que ponto o educativo se manifesta através das situações como um potencial ambiguo, difuso mas persistente. Neste sentido, analisar e tentar compreender 0 especiñcamente educativo implica também a consideração e a integração da avaliação no conjunto das suas características essenciais. Isto quer dizer que para que uma experiência seja educativa é necessário ter em conta a qualidade dessa experiência, o tipo de aprendizagem que tem lugar e a capacidade e riqueza do sujeito que a vive.

Ao nível da intenção, 0 educativo está, pois, principalmente no antes de qualquer acto; ao nível da avaliação, o educativo parece estar depois de qualquer acto. Mas, em educação, 0 antes segue e ganha sentido depois, constitui com ele uma unidade, e este, o depois ou consequência, é precedido educativamente por tudo 0 que 0 prepara e 0 torna possível; além de que 0 depois ou consequência começa em geral a funcionar desde 0 princípio, no próprio momento da identificação de uma situação ou relação como educativa, ou potencialmente educativa (cf. Damião, 1996). Aliás as actuais concepções de avaliação contínua e de avaliação formativa mais não são do que concretizações desta ideia. De modo que poderemos considerar que é em função do conjunto, e da interacção dos elementos que 0 constituem, que cada um destes factores ganha, ou perde, 0 seu verdadeiro significado educativo. Em ambos os casos isto quer dizer que há um educativo que paira acima do acto porque necessitou de um conjunto de circunstâncias prévias, que não se identificam com ele, e produziu ou destacou um conjunto de consequências, que persistem para lá dele, e que, por isso, tanto num caso como no outro são de algum modo exteriores a ele, e não se identificam completamente com nenhum acto em concreto; não resultam dele.

Em síntese, tentámos saber 0 que era 0 específicamente educativo. Se, nestas condições, o denominador comum do educativo, o que se mantém para além destes determinantes, é praticamente indefinível e as situações educativas são em número quase ilimitado, tal como os factores que as 
condicionam, o que deverá entender-se por específicamente educativo? E, nestas condições, que significado epistemológico poderá ter este conceito assim tão vasto e indefinido?

A função essencial do específicamente educativo pode ser somente a de referente, na medida em que é 0 grande englobante e, simultaneamente, 0 ponto de partida conceptual de todas as abordagens epistemológicas que à educação dizem respeito, isto é, que a ela revertem ou que dela derivam. Neste sentido, como conceito, define campos e estabelece condições; é factor de compreensão e de integração tanto de projectos, como de processos, como de retroacções; ou seja, é uma condição de acção, de fundamentação e de interpretação. Ora, este duplo estatuto de pedra de ara e de horizonte, de ponto de partida e de finalidade, este entendimento que engloba princípio e fim como essencial à sua própria compreensão, como condição da sua definição, estabelece uma autonomia de domínio, uma dinâmica cíclica e uma estrutura circular básica que garantem a sua especificidade. E a que, de algum modo, todos os contributos, científicos ou não, terão que se submeter, se quiserem ter valor educativo e levar à compreensão do que é a educação; porque é este 0 conceito dentro do qual e a partir do qual acção e conhecimento educativos ganham a sua real dimensão, e fora do qual não têm qualquer significado educativo. E isto tem sentido tanto numa perspectiva lógica, ou de fundamentação conceptual, que é a que estamos a desenvolver, como no ponto de vista de uma antropogénese, na linha de Fullat, por exemplo (1983; cf. também, Carvalho, 1992, Lopes, 2001). Com estas duas perspectivas, não só todo o tipo de conhecimento sobre 0 educativo ganha outra dimensão, como as modalidades de conhecimento que 0 educativo solicita, e as formas necessárias para investigar 0 próprio conhecimento nestas áreas, ficam assim dependentes destas referências.

Por certo que aquilo pelo qual o educativo se manifesta, enquanto problema, intenção, atitude ou prática, não se identifica com outras situações nem pode ser resolvido por elas. Também não se reduz a áreas de conhecimento específico ou a metodologias pedagógicas particulares, 
nem se mede pelos conhecimentos adquiridos ou pela quantidade de comportamentos transformados. Resiste ainda à explicação pelos factores de contexto, ou pelas perspectivas parcelares, mesmo que estas façam parte dele e sejam indispensáveis à sua compreensão, como frequentemente acontece.

Dá assim conta, a nível abstracto, e refere-se, a uma realidade educativa muito vasta e diversificada, na qual, porém, necessariamente se integram todos os estudos educativos, científicos ou não, e, em particular, as Ciências da Educação em toda a sua riqueza e diversidade, quer a investigação de que se servem seja quantitativa quer seja qualitativa, e as áreas científicas sejam nomotéticas, históricas ou filosóficas.

Deste modo, 0 especificamente educativo terá que ser 0 que está para além das explicações parcelares, ou mesmo de uma diversidade de explicações. Todas estas por certo possibilitam uma aproximação à sua compreensão, mas não 0 esgotam e, portanto, seguramente não 0 captam na sua essência, embora possibilitem a sua intuição. É, pois, como já se referiu, um estatuto ontológico que assim se constitui, mas não tanto em termos da definição de uma essência, de que se parte, e mais em ordem a uma funcionalidade, que se reconhece e se constitui nos limites da sua possibilidade; e não tanto a partir dos seus conteúdos educativos, mas sobretudo tendo como ponto de partida as potencialidades que os próprios conceitos determinam e solicitam. Tem, pois, as características de uma natureza que se manifesta, que se vai manifestando nos dados educativos, e que solicita processos de análise e de teorização em virtude tanto da sua componente abstracta quanto do seu potencial teórico.

\section{Abordagens práticas da questão}

Embora o especificamente educativo se compreenda ou deva ser entendido pela sua natureza abstracta e genérica, esta realidade torna-se 
mais compreensivel pela análise de certos problemas que a prática educativa e as respectivas situações podem suscitar. Aquilo que «faz» 0 educativo é 0 conjunto de circunstâncias concretas em que a educação sempre acontece, e, portanto, certas situações podem revelar, de maneira mais evidente, essa realidade de carácter ambíguo que, todavia, está sempre para lá delas.

Iremos ensaiar uma abordagem, ainda que exploratória, ao conceito de especificamente educativo pressuposto, por um lado, na formação e na profissão dos professores, e, por outro, no problema da especificidade didáctica que certas disciplinas implicam.

Em relação ao primeiro ponto, referir-nos-emos àquele domínio que diz respeito a um saber ser professor que nenhuma componente formativa cobre por completo, mas que resulta de uma série de contributos de várias áreas científicas, e de um conjunto de qualidades — modos de ser e de fazer — sobre as quais há um certo consenso, que são, contudo, difíceis de definir com rigor. No que ao segundo aspecto diz respeito -0 das didácticas - referiremos, como exemplo, uma disciplina onde 0 problema do ensino-aprendizagem levanta questões que vão para além das soluções propostas quer pela didáctica geral, quer por uma didáctica específica que dela pretenda decorrer. Ou melhor, tentaremos mostrar como a problemática das didácticas, habitualmente vista e resolvida de forma linear, ganha, em certas disciplinas, perspectivas particulares, e que, por vezes, é no escondido do problema que está a sua solução.

\subsection{Saber, saber fazer e saber ser professor}

Sem dúvida que é indispensável a um bom professor uma sólida formação científica, embora, como se sabe, esta não seja, só por si, suficiente para se ser um bom professor. Para lá dos problemas e dos conteúdos científicos de uma disciplina, e que o professor terá que dominar bem, colocam-se muitas questões psicopedagógicas, como as que se relacionam com os domínios 
psico-afectivo e sociocultural. Sabemos que os problemas de ensino e de aprendizagem das disciplinas estão entre os que mais preocupam os professores. Contudo, devem considerar-se de forma equilibrada as três componentes da formação: a científica, a psicopedagógica e a didáctica. Este equilíbrio nem sempre é conseguido ao nível da formação, mas terá que resultar de uma dosagem muito exigente para se conseguirem as atitudes adequadas.

Poucas vezes, como se sabe, estas componentes se articulam convenientemente, ouvindo-se frequentes queixas dos defensores da componente científica, de que se perde demasiado tempo de formação com as «pedagógicas». Os defensores destas, por sua vez, queixam-se do carácter elementar a que se reduz a formação educacional, tanto na componente teórica como na prática, ficando a formação dos professores a meio caminho de uma efectiva capacidade teórica e prática de assumir os problemas na sua complexidade e de os resolver da melhor maneira. Finalmente, a componente didáctica tenta frequentemente ganhar protagonismo à custa da formação educacional, reforçando 0 afunilamento de uma formação pela valorização do eixo científico-pedagógico específico, e a desvalorização, implícita, e mesmo explícita, do especificamente educativo, que está subjacente a muitas problemáticas psicopedagógicas, culturais e contextuais, ao seu significado e às suas implicações. Ora, não será por este «saber ser professor» que passa, neste caso, 0 especificamente educativo? E não será este que confere ao professor a capacidade de assimilar o equilíbrio das componentes científica, relacional e didáctica, indispensáveis à sua formação? Tal equilíbrio resultará por certo de uma síntese harmoniosa das três componentes formativas apresentadas, todas indispensáveis, ficando embora equidistante destas posições porque não se reduz a nenhuma delas e é mais do que a soma de todas, manifestando-se por um saber ser e um saber fazer que não será fácil de definir mas é relativamente fácil de identificar e de reconhecer.

Nesta perspectiva, o educativo é aquilo que confere 0 verdadeiro significado educativo à prática docente, aquilo que não se consegue obter se the faltar algo de significativo aos níveis científico, psicopedagógico e 
didáctico; mas, como se disse, não se esgota no seu conjunto. Antes de ser professor de matemática, por exemplo, todo 0 professor de matemática é educador; ele é educador antes, enquanto e depois de ser professor de matemática (ou de qualquer outra disciplina). Se um professor não compreende 0 verdadeiro significado do que é educar, não pode ser um bom professor. Se «uma lição ou um currículo, [ou as práticas de um professor] anulam os alunos, se fecham as suas mentes para 0 pensamento futuro, ou adormecem a sua sensibilidade, não podem considerar-se educativos» (Pring, 2003, 16). 0 que faz com que todas as actividades de ensino sejam verdadeiramente educativas é, «em primeiro lugar, a intenção de procurar uma aprendizagem; segundo, a sua conexão com a aprendizagem que se quer fomentar; terceiro, a relação dessas actividades com 0 estado mental e a motivação de quem aprende» (Pring, 2003, 41).

Se, por outro lado, uma acção educativa não frutificar numa maior vontade de conhecer, de compreender, numa maior sensibilidade à ciência, à cultura em geral, aos problemas humanos, talvez não se possa falar em «educativo», e 0 professor que não manifestar estas necessidades dificilmente cumprirá a sua missão. Mas isto implica um complexo equilibrado de intenções, de conhecimentos, de atitudes e de práticas, para além de uma sensibilidade, de uma humanidade e de uma cultura que, na sua síntese, se deverão aproximar desse educativo de que andamos à procura.

\subsection{A perspectiva didáctica}

As técnicas de ensinar nem sempre são meras questões de ordem didáctica, ou de uma didáctica específica que decorra de uma didáctica geral. Interessamos este tema porque as didácticas radicam no próprio processo ou acção de ensinar, com implicações práticas da maior importância.

É óbvio que algumas das questões colocadas pelas didácticas específicas se integram em questões mais vastas, as da didáctica geral. Mas será esta 
integração tão natural e óbvia como parece ser? A didáctica geral trata «de aspectos gerais da teoria de ensino-aprendizagem, aplicáveis ao conjunto de níveis de ensino e de matérias a ensinar» (Alarcão, 1994, 724), ou, como já dizia Nérici $(1968,53)$ consiste no «estudo de todos os princípios e técnicas válidos para 0 ensino de qualquer matéria ou disciplina». Por sua vez as didácticas específicas tratam do «estudo desses mesmos aspectos no âmbito de uma matéria específica, de um nível particular de ensino ou de um determinado tipo de alunos», (Alarcão, ibid, idem); ou da «aplicação dos princípios gerais da didáctica no campo de ensino de cada disciplina» (Nérici, 1968, 54). Ora, não haverá outra relação entre elas para além da de inclusão? E será que os princípios da didáctica geral e os das didácticas específicas são os mesmos, não passando de problemas de aplicação do geral às situações concretas? E que são estes os princípios gerais do ensino como transmissão natural, espontânea, directa, enquanto «método universal de ensinar tudo a todos», como dizia Coménio, (1985, 45)? Método que, segundo ele, derivando «da própria natureza imutável das coisas» (ibid., 46), proporcionaria uma aprendizagem «infalível», «rápida»e «sólida»? Ou seja, será que 0 aprender esgota todo 0 educativo? E que 0 aprender e 0 ensinar se relacionam directamente com essa «própria natureza imutável das coisas»? E não poderá colocar «essa natureza das coisas» problemas particulares que relevem do específicamente educativo enquanto entidade fluida que está, e não está, aparece e desaparece, que está muitas vezes onde não parece, e que desaparece facilmente de onde parece estar?

Tudo indica que a didáctica específica não resulta apenas, e em linha recta, da aplicação da didáctica geral; mas que, para lá disso, terá que entrar em conta com as disciplinas, as situações, os alunos, e o professor, pelo menos. Nem uma nem outra permitem compreender completamente os enquadramentos em que se desenvolve muita da problemática da arte de ensinar e de aprender uma matéria, sendo em geral estas questões muito mais complexas.

A perspectiva clássica da didáctica dá pouca atenção, por exemplo, à necessidade dos processos que Bernstein (1988) chama de recontextualização, 
ou a algo que está entre 0 domínio da produção científica e 0 da transmissão, ou melhor ainda, que está na confluência destes dois dominios solicitando sínteses funcionais para soluções adaptadas aos diferentes casos. Como se sabe, 0 conhecimento não é um dado imediato mas exige sempre uma estruturação por parte do sujeito. Embora preservando a exigência de rigor, a linguagem científica tem que ser transformada de modo a tornar-se significativa para o sujeito que aprende. Como tal, não é possível promover conhecimento unicamente na base do edifício linguístico da ciência. Além disso a questão não é só linguística, como não será so comunicacional, para referir outro exemplo. Tanto num caso como no outro não iremos muito além de uma didáctica que poderemos chamar clássica e, portanto, não tão longe da perspectiva de Coménio como possa parecer. A problemática educativa moderna, com toda a sua complexidade (a relação educativa, 0 desenvolvimento curricular, a psicologia do desenvolvimento, a avaliação, a aprendizagem ao longo da vida, etc.) tem-nos obrigado a reequacionar, e até a revolucionar, estes pontos de vista.

Sendo assim, será de rejeitar a perspectiva de um conhecimento de onde, quando e como aplicar, sem mais, certas técnicas pedagógicas, como se as coisas pudessem ser resolvidas por receituários abstractos. Do mesmo modo que não podemos ter a pretensão de uma cientificidade assente na ideia de que quem sabe as matérias sabe necessariamente ensiná-las, de que ensiná-las não é mais do que transmiti-las, e de que algumas regras básicas e gerais chegam para 0 sucesso.

É esta a posição acabada de quem desvaloriza 0 especificamente educativo, por não 0 reconhecer, ou por não compreender onde ele está ou onde possa estar, seja no professor, na matéria, no aluno ou, como geralmente acontece, numa inter-relação de várias triangulações e múltiplas combinatórias. E para cuja solução muitas ciências poderão contribuir, mas sempre em função de uma relação educativa, de uma situação e de uma meta que, relacionando-se entre si, são determinantes e condicionam todo 0 conjunto, numa síntese superadora, muito variável e de difícil captação. Esta teia de 
relações e de variáveis é, em si mesma, uma realidade específicamente educativa, que nenhuma ciência em particular pode compreender, mas que também escapa a uma simples multidisciplinaridade. Por isso em educação se fala, cada vez mais, de interdisciplinaridade e de transdisciplinaridade. Conceitos que, por sua vez, não têm grande sentido fora de uma dinâmica de problematização, de investigação e de prática educacional, em que 0 todo dessa mesma dinâmica -0 educativo — sobreleva as partes porque as reorganiza educativamente, isto é, dá-lhes o significado educativo que, de outro modo, lhes falta. Considere-se, por exemplo, as actuais dimensões da reforma educativa que apontam para a necessidade de projectos ao nível tanto da escola como da turma, (a área de projecto, a área da formação cívica e a ideia da transversalidade de certas formações); elas são a tentativa de aplicação deste conceito. É óbvio que muitas das reformas, que por vezes parecem avulsas, são manifestações de um pensamento educativo que se vai constituindo (quer nas suas componentes ideológicas quer científicas) e que está subjacente a todo este clima de mudança. É quase impossível, actualmente, com simples métodos clássicos, e dentro de uma perspectiva de didáctica geral, para além da indispensável formação científica, explorar as potencialidades educativas quer das disciplinas, quer dos alunos, quer dos professores (e dos adultos em geral), quer dos contextos e das situações, quer, finalmente, da relação entre todas estas realidades. As potencialidades teóricas desta dimensão são, para já, difíceis de calcular, mas são já intuídas por muita gente e estão a necessitar de uma conceptualização suficientemente abrangente. É o que propomos com este trabalho.

\subsection{0 caso da Filosofia}

Nesta perspectiva, um exemplo que nos parece sintomático é o do ensino da Filosofia porque, mais do que de uma variante da didáctica geral, tem necessidade, pela sua própria natureza, de uma abordagem diferente. 
0 que revela isto, porém, nâo é propriamente a Filosofia mas urna perspectiva pedagógica que tenha condições para realçar 0 específicamente educativo que a Filosofia encerra.

Num ponto de vista clássico, não se colocam ao ensino da Filosofia problemas didácticos diferentes dos das outras disciplinas. 0 próprio termo «didáctica» parece ter sido inventado para a Filosofia, porque vindo do verbo grego didaskô, ou arte de explicar e de discorrer, corresponde ao discurso mental de que a Filosofia necessita. Mas o educativo da Filosofia raramente se obtém utilizando este processo clássico, mas por uma via pedagógica que de certo modo inverte o seu esquema de ensino e de aprendizagem, como noutros lugares se pretendeu demonstrar (Boavida, 1991, 1996).

Se todo 0 problema estivesse em saber transmitir esses conteúdos com correcção, seguindo as regras clássicas da exposição, jamais entenderíamos 0 problema específico da Filosofia porque nem sequer chegávamos a entrar nele. Só uma exigência pedagógica, a partir da natureza da disciplina, dá à Filosofia a possibilidade de manifestar toda a sua potencialidade enquanto ensino e enquanto aprendizagem. Assim, 0 caso da Filosofia e da sua didáctica específica revela uma dimensão educativa que a própria afirmação do educativo da Filosofia muitas vezes esconde. Daí a ideia de que a revelação da Filosofia a quem nela se pretende iniciar passa por uma abordagem pedagógica que releva do específico educacional. Isto é, algo que nem está na pedagogia em si mesma, como 0 mostra a relação demasiado simples entre didáctica específica e a geral, quando a relação é de pura inclusão, nem na Filosofia propriamente dita, porque em si e por si mesma não exige a didáctica de que necessita, aparecendo o educativo como uma potencialidade que em certas circunstâncias se revela, e só nelas. Isto é, está lá, na natureza da própria Filosofia, mas 0 modo habitual de a abordar se encarrega de esconder 0 educativo que ela potencialmente contém. 


\section{Conclusão}

Para finalizar, poderíamos questionar-nos sobre a importância de proceder a uma análise deste tipo em torno do conceito de Educação, e do especificamente educativo; e deste, por sua vez, relativamente à problemática da razão profunda de uma teoria da educação. Respondemos, para já, um pouco na linha de Wilson (2003) ao colocar-se a si mesmo uma questão semelhante: «a resposta imediata é a de que 0 que fazemos é largamente determinado pelo modo como pensamos, e 0 que pensamos é determinado pelos conceitos que usamos, de tal forma que necessitamos de os entender meticulosamente se queremos que a nossa prática seja eficiente». Com efeito, raramente nos damos ao trabalho de pensar sobre os próprios conceitos que usamos, nem nos esforçamos muito por perceber a relação entre as mudanças nos campos social e educativo. Em tempos de mudança acelerada, como 0 nosso, torna-se indispensável procurar ideias claras. Mas estas, além de nem sempre serem claras, não são necessariamente distintas de outras, mais confusas, com as quais se misturam. Dada a grande complexidade do fenómeno educativo, a sua fugacidade e subtileza, e a multiplicidade de planos que se cruzam e se sobrepõem, muitas vezes 0 educativo esconde -se quando 0 julgamos ver e outras vezes vamos encontrá-lo nas situações mais inesperadas. Ou seja, o campo educativo é um domínio onde é indispensável analisar e teorizar, porque ao lado do subtil e do instável, de que temos experiência todos os dias, há constantes fundamentais que dizem respeito à estrutura e à função do acto educativo em si mesmo, e que sempre pressupomos apesar de toda a instabilidade verificada. É importante reconhecer esta realidade, como condição para poder atribuir (e identificar) 0 carácter educativo a todas as práticas, passadas ou actuais, que assim se possam designar, e, por outro lado, como condição para podermos projectar novas práticas com esse carácter educativo sempre integrado. 
Alarcão, I. (1994). A didáctica curricular na formação dos professores. In A. Estrela e J. Ferreira (Org.). Desenvolvimento Curricular e Didáctica das Disciplinas. Acta do IV Colóquio Nacional da AIPELF/AFIRSE (pp. 723-732). Faculdade de Psicologia e de Ciências da Educação da Universidade de Lisboa.

Bernstein, B. (1988). Clases, códigos y control (I y II vols.) Madrid: Akal.

Boavida, J. (1991). Filosofia - do ser e do ensinar, proposta para uma nova abordagem. Coimbra: INIC.

Boavida, J. (1996). Por urna didáctica para a filosofia - análise de algumas razões. Revista Filosófica de Coimbra, 9, pp. 91-110.

Coménio, J. A. (1985). Didáctica Magna. Lisboa: Fundação Calouste Gulbenkian (introdução e notas de J. Ferreira Gomes).

Carvalho, A.D. (1992). A Educação como Projecto Antropológico. Porto: Edições Afrontamento.

Damião, H. (1996). Pré, inter epós acção. Coimbra: Minerva.

Feldmann, D. (2003). Curriculum y objectivo: un viejo tema actual. Educ/ativa, 6, 2, pp. 185-199.

Fullat. 0. (1983). Filosofias de la educación. Barcelona: CEAC.

Lopes, B. (2001). A reconstrucão do sujeito. In A. D. Carvalho (Org.). Filosofia da Educação: Temas e Problemas. Porto: Edições Afrontamento.

Nérici, I. (1968). Introdução à didáctica geral - dinâmica da escola. São Paulo / Rio de Janeiro: Editora Fundo de Cultura.

Postic, M. (1984). A Relação Pedagógica. Coimbra: Coimbra Editora.

Pring, R. (2003). La educación como «práctica educativa». In Ma Garcia Amilburu (Ed.). Claves de la Filosofia de la Educación (29-48). Madrid: Editorial Dykinson.

Uljens, M. (2002). The idea of a universal theory of Education - an impossible but necessary project? Journal of the Philosophy of Education, 36, 3, pp. 353-375.

Wilson, J. (2003). The Concept of Education Revisited, Journal of Philosophy of Education, 37, 1, pp. 101-108. 